\title{
EFFECT OF HYDRALAZINE ON BLOOD FLOW, OXYGENATION, AND INTERSTITIAL FLUID PRESSURE IN SUBCUTANEOUS TUMORS
}

\author{
Tomaž Jarm, Blaž Podobnik, Gregor Serša, and Damijan Miklavčič ${ }^{*}$
}

\section{INTRODUCTION}

Many experimental and clinical solid tumors are known to exhibit poor oxygenation ${ }^{1-3}$ and high interstitial fluid pressure ${ }^{4,5}$ (IFP) in comparison to normal surrounding tissues. Oxygenation and IFP in addition to abnormal blood flow influence the response of tumors to various therapies and are also important for development and progression of malignant growth. ${ }^{1-5}$ Hydralazine (HYZ) is an arteriolar vasodilating drug which is used for treatment of hypertension in humans. ${ }^{6} \mathrm{HYZ}$ can decrease both tumor blood flow ${ }^{7-10}$ and tumor IFP. ${ }^{9,11}$ These two changes may have opposite effects on drug delivery and oxygenation in tumors. In our study we evaluated the effect of HYZ on blood flow, oxygenation, and IFP in a murine tumor model. Oxygenation was measured by a relatively new method which has recently become available, the OxyLite system. ${ }^{12,13}$

\section{MATERIALS AND METHODS}

\subsection{Tumor model and anesthesia}

The study was performed on solid subcutaneous SA-1 fibrosarcoma tumors (Jackson Lab., Bar Harbor, U.S.A.) growing dorsolaterally in the right flank of A/J mice (Rudjer Boskovic Inst., Zagreb, Croatia). Tumors were inoculated by injection of $5 \times 10^{5}$ viable SA-1 cells. Measurements were performed 8-10 days after inoculation when the tumors reached a volume of approximately $100 \mathrm{~mm}^{3}$. Mice were anesthetized during experiments by isoflurane (concentration $1.7 \%$ ) delivered via a miniature face mask in a mixture of $\mathrm{O}_{2}$ and $\mathrm{N}_{2} \mathrm{O}$. Physiological temperature of mice was maintained by a regulated heating pad. At the end of experiments the mice were euthanized under anesthesia by cervical

\footnotetext{
Tomaž Jarm, Blaž Podobnik, and Damijan Miklavčǐ, Faculty of Electrical Engineering, University of Ljubljana, Tržaška 25, Ljubljana, Slovenia SI-1000. Gregor Serša, Institute of Oncology, Zaloška 2, Ljubljana, Slovenia SI-1000.
} 
dislocation. Experimentation on mice was conducted in accordance with the pertaining legislation and was approved by the Veterinary Administration of Ministry of Agriculture, Forestry and Food of Slovenia (permit number 323-02-156/99).

\subsection{Measurement methods}

Relative blood flow in tumors was measured by laser Doppler flowmetry (LDF). A two-channel instrument OxyFlo (Oxford Optronix, U.K.) was used in our study with invasive bare optical fiber sensors (diameter $0.2 \mathrm{~mm}$ ).

Partial pressure of oxygen $\left(\mathrm{pO}_{2}\right)$ in tumors was measured by a novel luminescencebased fiber-optic technique. This method employs a ruthenium luminophore, which is incorporated in a silicone cap fixed to the tip of a fiber-optic sensor. ${ }^{12,13}$ Pulses of blue light carried via the fiber excite pulsatile fluorescence of the luminophore. The life-time of this fluorescence is inversely proportional to local $\mathrm{pO}_{2}$ in tissue in contact with the probe tip. The advantage of this method over the well established polarographic oximetry is that the fiber-optic $\mathrm{pO}_{2}$ sensor does not consume oxygen and should therefore enable continuous monitoring of $\mathrm{pO}_{2}$. A two-channel instrument OxyLite with combined $\mathrm{pO}_{2}$ and temperature sensors (diameter $0.3 \mathrm{~mm}$ ) were used in our study (Oxford Optronix, U.K.).

Interstitial fluid pressure (IFP) in tumors was measured by the so-called "wick-inneedle" technique. ${ }^{11,{ }^{14}}$ The system used in our study consisted of needle probes (diameter $0.5 \mathrm{~mm}$ ), TSD104A pressure transducers, a DA100A amplifier, and an MP100 data acquisition unit (Biopac Systems, U.S.A.).

All probes were inserted into tissue approximately 5 minutes after the start of anesthesia in mice. The IFP probe was inserted into tumor from the caudal side. Both $\mathrm{pO}_{2}$ and both LDF probes were inserted into tumor from the cranial side. All probes were slightly withdrawn after insertion to minimize tissue compression.

\subsection{Hydralazine treatment}

Hydralazine (Sigma Chemical, U.S.A.) was dissolved in sterile physiological saline and injected $i . v$. at a dose of $2.5 \mathrm{mg} / \mathrm{kg}$ of mouse weight. Control mice were injected with physiological saline only. Injections were made during measurements and only if all recorded signals had been stable for at least 10 minutes prior to injection.

\section{RESULTS AND DISCUSSION}

After injection of hydralazine (HYZ) blood flow started to decrease in all measurement locations. On average blood flow decreased by 50\% within 5-10 minutes (Fig. $1 \mathrm{a}$ ). No change was observed in control tumors. The results are in good agreement with the previously documented effect of $\mathrm{HYZ}$ on tumor blood flow. ${ }^{710}$

Two distinct types of $\mathrm{pO}_{2}$ signals were observed after insertion of a probe into tumor (Fig. 2). First, $\mathrm{pO}_{2}$ decreased within one minute to near zero level in all cases (the decrease phase). In about $1 / 3$ of measurements this near-to-zero $\mathrm{pO}_{2}$ (the zero $\mathrm{pO}_{2}$ phase) was maintained during the whole period of observation (the type II signals). In the remaining $2 / 3$ of measurements (the type $I$ signals) $\mathrm{pO}_{2}$ started to increase after 5-20 minutes (the increase phase) and finally stabilized at a new level (the plateau phase) 20 30 minutes after insertion of the probe. This plateau phase $\mathrm{pO}_{2}$ varied among different 

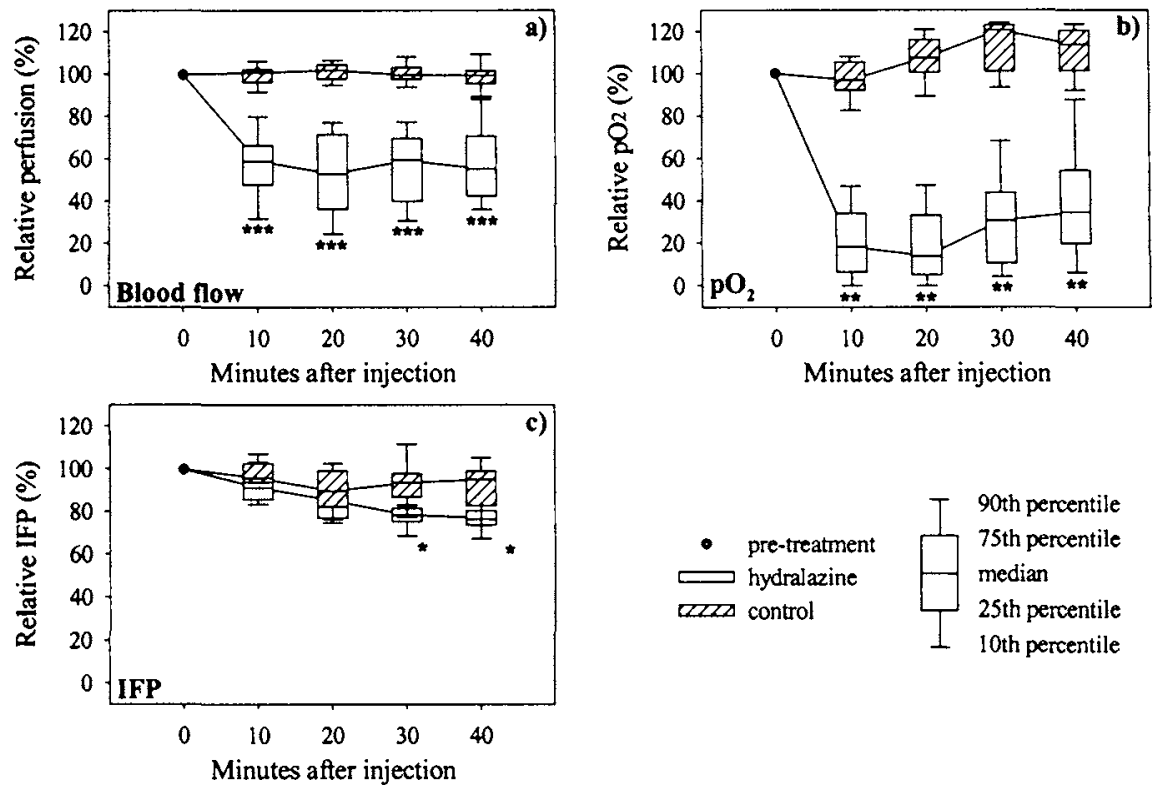

Figure 1. The effect of hydralazine on blood flow (a), oxygenation (b), and interstitial fluid pressure (c) in tumors. All individual values measured after injection were expressed relatively with respect to the pretreatment value $(100 \%)$ before averaging. Statistical significance of differences between HYZ-treated and control tumors was calculated by Mann-Whitney rank sum test $\left({ }^{*} p<0.05,{ }^{* *} p<0.01,{ }^{* * *} p<0.001\right)$.
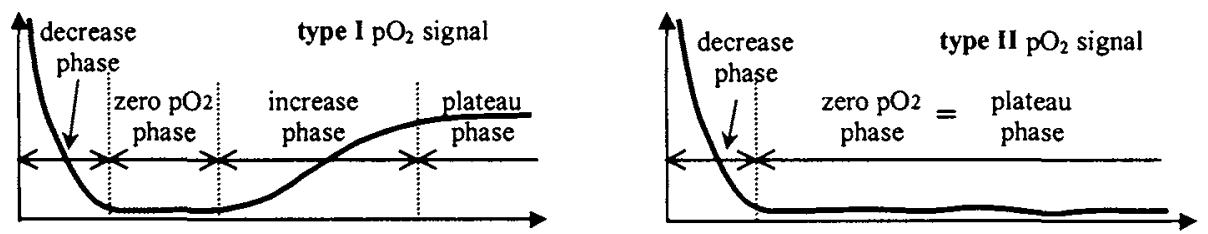

Figure 2. Two characteristic types of $\mathrm{pO}_{2}$ signal as a function of time encountered in tumors after insertion of the sensor into tumor. Lengths of individual phases in type I signal are not proportional.

Table 1. Averaged changes in blood flow, oxygenation, and IFP measured in tumors 40 minutes after injection of either hydralazine (HYZ) or physiological saline (control).

\begin{tabular}{|c|c|c|c|c|c|c|c|}
\hline \multirow[b]{2}{*}{ parameter } & \multirow[b]{2}{*}{ group } & \multirow[b]{2}{*}{$\mathrm{n}$} & \multicolumn{2}{|c|}{ pre-injection $^{A}$} & \multicolumn{2}{|c|}{ post-injection ${ }^{\mathbf{A}}$} & \multirow[b]{2}{*}{$p^{c}$} \\
\hline & & & median & $25-75 \%{ }^{8}$ & median & $25-75 \%$ & \\
\hline blood flow (BPU) & $\begin{array}{c}\text { HYZ } \\
\text { control }\end{array}$ & $\begin{array}{c}17 \\
8\end{array}$ & $\begin{array}{l}245 \\
540\end{array}$ & $\begin{array}{l}120-431 \\
341-790\end{array}$ & $\begin{array}{l}138 \\
545\end{array}$ & $\begin{array}{c}88-331 \\
338-766\end{array}$ & $\begin{array}{c}<0.001 \\
0.938\end{array}$ \\
\hline $\mathrm{pO}_{2}(\mathrm{mmHg})$ & $\begin{array}{c}\mathrm{HYZ} \\
\text { control }\end{array}$ & $\begin{array}{c}13 \\
6\end{array}$ & $\begin{array}{l}17.7 \\
22.2\end{array}$ & $\begin{array}{c}2.9-36.6 \\
13.6-32.7\end{array}$ & $\begin{array}{c}4.6 \\
27.3\end{array}$ & $\begin{array}{c}0.4-11.0 \\
14.9-36.8\end{array}$ & $\begin{array}{c}<0.001 \\
0.109\end{array}$ \\
\hline IFP (mmHg) & $\begin{array}{c}\text { HYZ } \\
\text { control }\end{array}$ & $\begin{array}{c}11 \\
6\end{array}$ & $\begin{array}{l}10.5 \\
10.1\end{array}$ & $\begin{array}{l}6.6-13.0 \\
6.3-11.5\end{array}$ & $\begin{array}{l}8.2 \\
8.8\end{array}$ & $\begin{array}{l}5.2-9.7 \\
6.0-9.6\end{array}$ & $\begin{array}{c}<0.001 \\
0.219\end{array}$ \\
\hline
\end{tabular}

\footnotetext{
${ }^{\lambda}$ Pre- and post-injection means just before injection and 40 minutes after injection respectively.

B The spread of data around the median value is given with the $25^{\text {th }}$ and the $75^{\text {th }}$ percentile limits.

c Statistical significance of change from the pre- to the post-treatment value (Wilcoxon signed rank test).
} 
measurement locations between 1.5 and $60 \mathrm{mmHg}$. Both type I and type II signals were sometimes encountered within the same tumor. A very similar distinction between the two types of $\mathrm{pO}_{2}$ signals in tumors has been reported by Seddon et al.. ${ }^{15}$ In our study the median $\mathrm{pO}_{2}$ value from 40 measure-ment locations was $10.3 \mathrm{mmHg}$ with the $\mathrm{pO}_{2}<2.5$ mmHg fraction being $40 \%$. The effect of $\mathrm{HYZ}$ could only be observed in type I signals. In type I signals the $\mathrm{pO}_{2}$ decreased to $20 \%$ of the pre-treatment level within 5-10 minutes after injection (Fig. 1b). No change was seen in type I signals in control tumors. The observed decrease in $\mathrm{pO}_{2}$ was well correlated with the blood flow decrease and is in agreement with the published results showing that metabolic activity in tumors due to HYZ was decreased ${ }^{16}$ and that the effectiveness of hypoxic cell-specific treatment in tumors was increased by HYZ. $8,10,17$

A decrease was also observed in IFP after injection of HYZ (Fig. 1c) but the difference between HYZ-treated and control tumors was not as pronounced as with blood flow or oxygenation. On average the minimum level of IFP was observed 30-40 minutes after injection. These results are in agreement with previously published data. ${ }^{9,11}$

Averaged absolute values of blood flow, $\mathrm{pO}_{2}$, and IFP in tumors before treatment and 40 minutes after treatment are shown in Table 1 . In the conditions of decreased systemic blood pressure caused by HYZ the organism tries to maintain normal blood flow in vital organs by reducing the blood flow to less critical tissues. ${ }^{16}$ This "steal" effect is most probably responsible for the observed decrease in tumor blood flow and subsequently for the decrease in tumor $\mathrm{pO}_{2}$.

The initial decrease of $\mathrm{pO}_{2}$ immediately after the insertion of the probe is due mostly to the consumption of oxygen brought into tissue during the insertion. The multiphase behavior of type $\mathrm{I} \mathrm{pO}_{2}$ signals during the stabilization period after this initial decrease was most probably a result of tissue damage caused during the insertion of probes into tissue. Torn and occluded capillaries ${ }^{18,19}$ and vasoconstrictive reactions ${ }^{15}$ may lead to decreased blood flow and deoxygenation of tissue in immediate vicinity of the insertion track and at the probe tip (the zero $\mathrm{pO}_{2}$ phase in type I signals). Afterwards the tissue may be reoxygenated (the increase $\mathrm{pO}_{2}$ phase) due to gradual restoration of microcirculation but it is not yet clear how well the level of $\mathrm{pO}_{2}$, reached in the plateau phase represents the $\mathrm{pO}_{2}$ before insertion of the probe. The type II $\mathrm{pO}_{2}$ signals most probably originated from truly hypoxic regions in tumors. Blood flow never exhibited the multiphase behavior encountered in type $\mathrm{I} \mathrm{pO}_{2}$ signals. The most likely reason is that the tissue sampling volume of the LDF method is larger than that of the new optical $\mathrm{pO}_{2}$ sensor.

The relatively high IFP in tumors in comparison to normal tissue was associated with poor oxygenation and resistance of tumors to radiotherapy, and with insufficient blood flow and impaired delivery of chemotherapeutic drugs to tumor cells. ${ }^{4,5}$ Elevated IFP in tumors can contribute to development of hypoxia in tumors by decreasing the blood flow. ${ }^{4,5}$ Decreasing the elevated IFP may therefore improve tumor oxygenation. Application of HYZ in our study, however, decreased both the IFP and the $\mathrm{pO}_{2}$ in tumors.

\section{CONCLUSIONS}

Blood flow, oxygenation, and IFP in SA-1 tumors in A/J mice were decreased by HYZ. The pronounced decrease in blood flow indicates that delivery of a chemotherapeutic drug and oxygen would be severely impaired by HYZ at the dosage used. The measured decrease in oxygenation proves that. Even though the new luminescence-based 
fiber-optic oximetry proved to be useful for detection of oxygenation changes, further investigation is needed to verify the absolute $\mathrm{pO}_{2}$ values measured by this method.

\section{ACKNOWLEDGEMENT}

This study was supported by the Ministry of Education, Science and Sport of the Republic of Slovenia (grant J2-2222-1538) and by the European Commission and the $5^{\text {th }}$ Framework Programme (grant QLK 3-99-00484, CLINIPORATOR project).

\section{REFERENCES}

1. M. R. Horsman, Measurement of tumor oxygenation, Int. J. Radiat. Oncol. Biol. Phys, 42, $701-704$ (1998).

2. M. Höckel, B. Vorndran, K. Schlenger, E. Baußmann, and P. G. Knapstein, Tumor oxygenation: a new predictive parameter in locally advanced cancer of the uterine cervix, Gynecol. Oncol. 51, 141-149 (1993).

3. P. Vaupel, D.K. Kelleher, and O. Thews, Modulation of tumor oxygenation, Int. J. Radiat. Oncol. Biol. Phys. 42, 843-848 (1998).

4. L. T. Baxter and R. K. Jain, Transport of fluid and macromolecules in tumors I. Role of interstitial fluid pressure and convection, Microvasc. Res. 37, 77-104 (1989).

5. M. F. Milosevic, A. W. Fyles, and R. P. Hill, The relationship between elevated interstitial fluid pressure and blood flow in tumors: a bioengineering analysis, Int. J. Radiat. Oncol. Biol. Phys. 43, 1111-1123 (1999).

6. R. F. Albrecht, E.T. Toyooka, S. L. H. Polk, and B. Zahed, Hydralazine therapy for hypertension during the anesthetic and postanesthetic periods, Int. Anesthesiol. Clin. 16, 299-312 (1978).

7. M. J. Trotter, B. D. Acker, and D. J. Chaplin, Histological evidence for nonperfused vasculature in a murine tumor following hydralazine administration, Int. J. Radiat. Oncol. Biol. Phys. 17, 785-789 (1989).

8. J. Kalmus, P. Okunieff, and P. Vaupel, Dose-dependent effects of hydralazine on microcirculatory fuction and hyperthermic response of murine FSaII tumors, Cancer Res. 50, 15-19 (1990).

9. R. A. Zlotecki, L. T. Baxter, Y. Boucher, and R. K. Jain, Pharmacologic modification of tumor blood flow and interstitial fluid pressure in a human tumor xenograft: network analysis and mechanistic interpretation, Microvasc. Res. 50, 429-443 (1995).

10. M. R. Horsman, K. L. Christensen, and J. Overgaard, Relationship between the hydralazine-induced changes in murine tumor blood supply and mouse blood pressure, Int. J. Radiat. Oncol. Biol. Phys. 22, 455-458 (1992).

11. B. Podobnik and D. Miklaveic, Influence of hydralazine on interstitial fluid pressure in experimental tumors - a preliminary study, Radiol. Oncol. 34, 59-65 (2000).

12. D. R. Collingridge, W. K. Young, B. Vojnovic, P. Wardman, E. M. Lynch, S. A. Hill, and D. J. Chaplin, Measurement of tumor oxygenation: a comparison between polarographic needle electrodes and a timeresolved luminescence-based optical sensor, Radiat. Res. 147, 329-334 (1997).

13. J. R. Griffiths and S. P. Robinson, The OxyLite: a fibre-optic oxygen sensor, Br. J. Radiol. 72, 627-630 (1999).

14. H. O. Fadnes, R. K. Reed, and K. Aukland, Interstitial fluid pressure in rats measured with a modified wick technique, Microvasc. Res. 14, 27-36 (1977).

15. B. M. Seddon, D. J. Honess, B. Vojnovic, G. M. Tozer, and P. Workman, Measurement of tumor oxygenation: in vivo comparison of a luminescence fiber-optic sensor and a polarographic sensor and a polarographic electrode in the P22 tumor, Radiat. Res. 155, 837-846 (2001).

16. P. Okunieff, C. S. Walsh, P. Vaupel, F. Kallinowski, B. M. Hitzig, L. J. Neuringer, and H. D. Suit, Effects of hydralazine on in vivo tumor energy metabolism, hematopoietic radiation sensitivity, and cardiovascular parameters, Int. J. Radiat. Oncol. Biol. Phys. 16, 1145-1148 (1989).

17. D. J. Chaplin and B. Acker, The effect of hydralazine on the tumor cytotoxicity of the hypoxic cell cytotoxin RSU-1069: evidence for therapeutic gain, Int. J. Radiat. Oncol. Biol. Phys. 13, 579-585 (1987).

18. F. Steinberg, E. Hildenhagen-Britggemann, and M. A. Konerding, Oxygen electrode injury in tumour tissue, in: Tumor oxygenation, edited by O. Thews, D. K. Kelleher, and P. W. Vaupel (Gustav Fischer Verlag, Stuttgart, 1995), pp. 186-193.

19. U. Schramm, W. Fleckenstein, and C. Weber, Morphological assessment of skeletal muscular injury caused by $\mathrm{pO}_{2}$ measurements with hypodermic needle probes, in: Clinical oxygen measurement II, edited by A. M. Ehrly, W. Fleckenstein, J. Hauss, and R. Huch (Blackwell Ueberreuter Wissenschaft, Berlin, 1990), pp. 38-50. 